Original Articles

\title{
Assessing and predicting changes in ecosystem service values based on land use/cover change in the Bohai Rim coastal zone
}

\author{
Yubin Liu ${ }^{\mathrm{a}, \mathrm{b}, \mathrm{c}}$, Xiyong Hou ${ }^{\mathrm{a}, \mathrm{c}, \mathrm{e}, *}$, Xiaowei $\mathrm{Li}^{\mathrm{a}, \mathrm{c}, \mathrm{e}}$, Baiyuan Song ${ }^{\mathrm{a}, \mathrm{b}, \mathrm{c}}$, Chao Wang ${ }^{\mathrm{d}}$ \\ ${ }^{a}$ Yantai Institute of Coastal Zone Research, Chinese Academy of Sciences, Yantai 264003, Shandong, China \\ ${ }^{\mathrm{b}}$ University of Chinese Academy of Sciences, Beijing 100049, China \\ ${ }^{\mathrm{c}}$ Key Laboratory of Coastal Environmental Processes and Ecological Remediation, CAS, Yantai 264003, Shandong, China \\ d College of Geography and Environment, Shandong Normal University, Ji'nan 250014, China \\ ${ }^{\text {e } C e n t e r ~ f o r ~ O c e a n ~ M e g a-S c i e n c e, ~ C A S, ~ Q i n g d a o ~ 266071, ~ C h i n a ~}$
}

\section{A R T I C L E I N F O}

\section{Keywords:}

Bohai Rim coastal zone

Land use/cover change

Scenario simulation

Ecosystem service

\begin{abstract}
A B S T R A C T
Land use/cover change (LUCC) in the Bohai Rim coastal zone has accelerated as a result of rampant economic development, which has directly caused many negative effects on ecosystem functions and services. Based on multi-temporal land use data (2000, 2005, 2010 and 2015), the benefit transfer method was used to assess the ecosystem service value (ESV) of the Bohai Rim coastal zone, and the impact of LUCC on ecosystem services was studied. Multi-scenario simulations for 2025 were conducted using the future land use simulation model. The result of the analysis showed that during the period from 2000 to 2015, the total ESV lost was 22.09 billion yuan, representing a decrease of 3.80\%. The spatial distribution of the ESV showed a certain regularity, with obvious characteristics of a land-sea gradient change. As the distance from the coastline increased, the ESV per unit area gradually declined. Compared with those in 2015, the total ESVs of the socio-economic development scenario and the business-as-usual scenario in 2025 showed a declining trend, while they increased under the ecological protection priority scenario. Under the ecological protection priority scenario, regulating services and support services increased significantly, but those declined dramatically under the socio-economic development scenario. The patterns of LUCC are the main reasons for the decrease in ESV. This research provides a theoretical basis and support for the development and utilization of coastal space and the improvement of "ecologicaleconomic-social" benefits; additionally, the results provide support for scientific decision-making services for the sustainable use of resources in the coastal zone and for the sustainable management of ecosystems.
\end{abstract}

\section{Introduction}

Ecosystem services refer to the natural environmental conditions and functions formed and maintained by the ecosystem and processes for human survival, including provisioning services (e.g., food, fresh water and fuel), regulating services (e.g., climate regulation, water purification and pollination), cultural services (e.g., recreation cultural heritage and inspirational value), and supporting services (e.g., soil formation and provision of habitat) (Millennium Ecosystem Assessment, 2005; Xie et al., 2015). The sustainable development of the social economy depends on the sustainable supply of ecosystem services (Yan et al., 2017). However, over the past 100 years, global climate change (Boone et al., 2018), environmental pollution (Escobedo et al., 2011), ecological destruction (Bussmann, 1996), resource depletion (de Araujo Barbosa et al., 2016), and land use/cover change (LUCC) (Dadashpoor et al., 2019) have had a tremendous impact on ecosystem functions and consequently have led to changes in ecosystem services. The Millennium Ecosystem Assessment (MA) report showed that more than $60 \%$ of the global ecosystems are or have been degraded, and one of the main causes for this degradation is disruptions by human activities (Millennium Ecosystem Assessment, 2005). Furthermore, the Intergovernmental Science-Policy Platform on Biodiversity and Ecosystem Services (IPBES) Global Assessment report showed that threequarters of the land-based environment and approximately $66 \%$ of the marine environment have been significantly altered by human actions. Some serious damage to the environment by human beings has reached or even exceeded the ecosystem carrying capacity, and some ecosystems have reached an irreversible amount of damage. In recent decades, research on ecosystem service functions has received more attention than ever before. Costanza et al. proposed the classification of ecosystem service values (ESVs) and the method of economic value evaluation, which provided new ideas and methods for the study of ESVs

\footnotetext{
* Corresponding author at: Yantai Institute of Coastal Zone Research, Chinese Academy of Sciences, ChunHui Road 17\#, Laishan District, Yantai, Shandong, China.

E-mail address: xyhou@yic.ac.cn (X. Hou).
} 
(Costanza et al., 1997). Since then, ESVs have been extensively studied globally and have become a popular and cutting-edge issue for global or regional organizations and their scientific communities (Li et al., 2017; Odgaard et al., 2017; Song, 2018).

LUCC is a crucial way in which human activities affect ecosystems, and LUCC changes the supply of ecosystem products and services by influencing ecosystem patterns and processes (Li et al., 2018). The MA report noted that LUCC has been the most important driving force of the change in terrestrial ESV since the 1950s (Millennium Ecosystem Assessment, 2005). The integration of LUCC and ecosystem services research has been greatly facilitated by the implementation of a range of international projects, such as the Global Land Project (GLP), The Economics of Ecosystems and Biodiversity (TEEB), and the IPBES. Global scholars have focused increasing attention on the impact of LUCC on ecosystem services and have conducted extensive research on the global scale, national scale, regional scale and watershed scale, achieving remarkable results (de Groot et al., 2012; Song and Deng, 2017). However, most research has focused on terrestrial ecosystem services, and there has been less research on coastal and offshore marine ecosystem services (Suo et al., 2011; Li et al., 2016).

Coastal ecosystems (including terrestrial coastal wetlands and shallow waters) play an irreplaceable role in material production, climate regulation, water conservation, pollutant removal, biodiversity maintenance and other factors, and are some of the most valuable natural ecosystems on Earth. However, more than half of the world's population, production and consumption activities are concentrated in coastal zones that account for less than $10 \%$ of the global area (Cohen, 2006). This has led to a series of ecological and environmental problems, especially the destruction of the components and structures of the natural ecosystem, and the weakening or the partial or total loss of ecosystem services (Dittman et al., 2015).

Over recent decades, China's coastal zone, with sustained and rapid population growth, has experienced unprecedented intensive development (e.g., rapid urbanization, over reclamation, and construction of manufacturing facilities and mines), leading to the prominence of problems with the ecological environment; these problems have seriously threatened the sustainable economic and social development of the region (Wang et al., 2015). Under intensive development activities, the LUCC has been among the most important perceptible change occurring on the Earth's surface (Roy et al., 2010). The transformation of land use types has direct economic benefits for human beings, and at the same time, it greatly changes or even causes imbalances in ecosystem services. These changes or imbalances are embodied in water resources, air quality, disaster prevention, biodiversity and other aspects, and they affect human well-being. The Bohai Rim coastal zone was selected as the study area because it is a typical area for the highintensity development of human activities in the coastal zone of China. The main objectives of this study are to assess the ESV of the Bohai Rim coastal zone, predict the future distribution of LUCC by multi-scenario simulation analysis, and estimate variations in ESV resulting from the impacts of LUCC on the Bohai Rim coastal zone.

\section{Materials and methods}

\subsection{Study area}

The Bohai Rim region is a "C"-shaped region composed of the Liaodong Peninsula, the Shandong Peninsula and the North China Plain. The Bohai Sea is a semi-enclosed inland sea in China, that is divided into five parts: Liaodong Bay, Bohai Bay, Laizhou Bay, the Central Bohai Sea and the Bohai Strait (Zhang et al., 2002). The ecosystems around the Bohai Sea are an important part of the overall ecosystem of northern China. The main types of ecosystem in this area include estuarine delta wetland, farmland, aquaculture pond, salt pan, coastal mountain forest, coastal beaches and towns, which provide many ecosystem products and services (Suo et al., 2011).

The Bohai Rim region is an important industrial and agricultural base in China that has rich marine biological resources, mineral resources, oil-gas resources, coal resources and tourism resources. With Beijing and Tianjin at the centre, this region is an important economic zone, with a relatively concentrated population and increasingly concentrated industries, in eastern China. The Bohai Economic Rim or the Bohai Bay Economic Rim is rapidly emerging and is becoming the third largest metropolitan economic zone in China, following the "Yangtze River Delta" and "Pearl River Delta" urban economic zones (Guo et al., 2009).

With the rapid development of urbanization and industrialization around the Bohai Rim region, coastal development activities have become more and more frequent, land use has changed significantly, and the ecological environment is facing unprecedented pressure. A large number of land-based pollutants are being discharged, resulting in water pollution in coastal waters, declining fishery resources, and a sharp decline in biodiversity. Frequent marine disasters (such as red tides, oil spills, etc.) have put great pressure on the offshore ecological environment (Mei and Yin, 2009; Zhang and Zhang, 2014). Unreasonable marine development and utilization activities, such as large-scale cofferdams and damming, have resulted in a large loss of coastal wetlands. These factors have led to continuous declines in the ecosystem service functions and the sustainable uses of the Bohai Sea and threaten the economic and social development of the region around the Bohai Sea (Gai et al, 2018).

The Bohai Rim coastal zone was selected as the study area, and the boundary of the zone was defined considering both the research needs and the actual situation of the research area. The land area is bordered by district and county administrative divisions, and the sea area boundary is underwater at the $10 \mathrm{~m}$ isobath. The study area includes 110 counties and districts in three provinces and one city (i.e., Liaoning, Hebei, Shandong and Tianjin, respectively) (Fig. 1).

\subsection{Data collection}

The LUCC data are used for LUCC multi-scenario simulation analysis and ESV assessment. The LUCC data source is the China Coastal Land Use Data Set, which has established data products for 2000, 2005, 2010 and 2015, and has divided the LUCC of the coastal zone of China into 8 first-level types and 24 s-level types (Di et al., 2014; Di et al., 2015; Hou et al., 2018). In this paper, shallow sea water was listed separately so that the types of LUCC were reclassified into 9 categories: farmland, forest land, grassland, inland freshwater, saltwater wetland, shallow water, human-made wetland, built-up land and unused land. The driving force factor data set for LUCC multi-scenario simulations were selected according to the actual situation of existing research and research areas and considering the availability of data (Su et al., 2016). A total of 8 driving factors were selected, including the digital elevation model (DEM) (http://www.gscloud.cn/), slope (generated by the DEM), population density (http://www.resdc.cn/), temperature and precipitation (http://www.resdc.cn/), distance to town, distance to traffic, and distance to a water system (extracted from land use data, obtained by Euclidean Distance Analysis).

\subsection{Ecosystem service valuation}

There are three main methods used to evaluate the ESVs: energy value analysis method, physical assessment method and value assessment method (Cui, 2005). The value assessment method includes the functional price method and the equivalent coefficients table method (Xie et al., 2017). The functional price method has more input parameters and a complicated calculation process. In contrast, the equivalent coefficients table method is more intuitive and easier to use, as it has fewer data requirements and is particularly suitable for the 


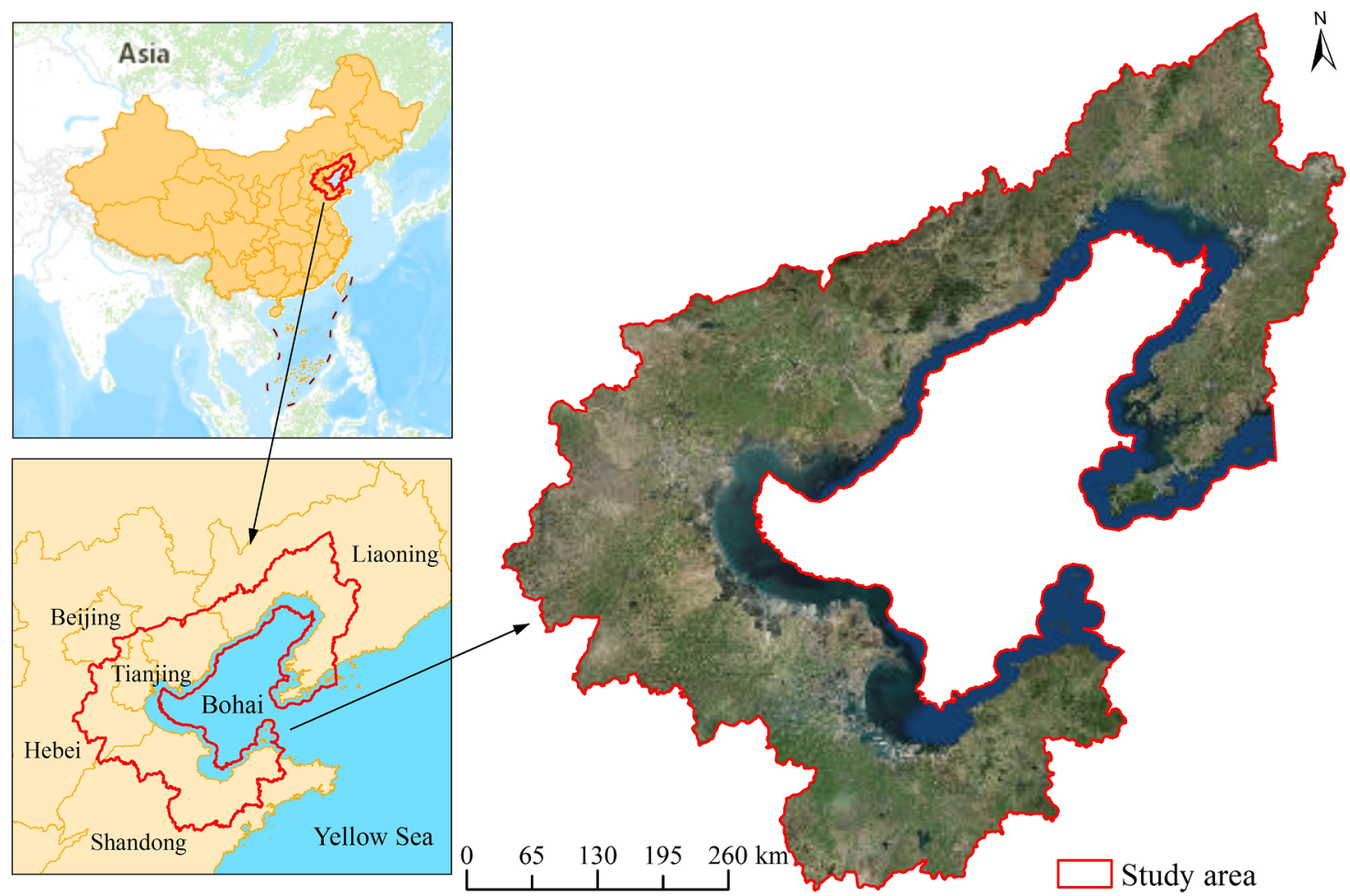

Fig. 1. Location of the Bohai Rim coastal zone.

assessment of ESVs at the regional and global scales. The equivalent coefficients table method is more directly and easily understood and accepted by the public. Therefore, this paper adopted the equivalent coefficients table method to estimate the ESVs.

Costanza et al. estimated the ESVs on a global scale. To reduce the errors caused by applying this method to China, Xie et al. (2015) revised it by using a questionnaire survey of domestic ecological scholars to obtain the equivalent coefficients table of the ecosystem services that are applicable to China, and this information has been widely used in China. Therefore, the values per unit area of ecosystem services that were used in this study refer to this previous research. Then, the standard equivalent factor was determined, mainly using the average net profit per unit area (2015 price level) of the three major foods (rice, wheat and corn) from 2000 to 2015 , with a value of 2181.78 yuan $/ \mathrm{hm}^{2}$ (Xie et al., 2017). The unit area values of land use/cover types not covered by this equivalent coefficients table were directly obtained by BTM, including those for shallow waters (Zhang et al., 2015a,b) and human-made wetland (including saltern/salt pan and aquaculture ponds) (Li, 2011), in which the service value coefficient of built-up land was 0 . Finally, the value tables of the ecosystem services per unit area of different land use types were obtained (Table 1). The ESV was calculated using the following equations:

$$
\begin{aligned}
& E S V_{k}=\sum_{f} A_{k} \times V C_{k f} \\
& E S V_{f}=\sum_{k} A_{k} \times V C_{k f} \\
& E S V=\sum_{k} \sum_{f} A_{k} \times V C_{k f}
\end{aligned}
$$

where $E S V_{k}, E S V_{f}$ and $E S V$ refer to the $E S V$ of the type k ecosystems, the ability category of $E S V_{f}$, and the total $E S V$, respectively. $A_{k}$ is the area (in ha) of the type $\mathrm{k}$ ecosystem, and $V C_{k f}$ (Chinese yuan $/ \mathrm{hm}^{2}$ ) denotes the value coefficient for land use type $k$ and ecosystem service function type $f$.

\subsection{Land use/cover change multi-scenario simulation}

LUCC simulation models are effective and reproducible tools for analysing both the causes and the consequences of future landscape dynamics under various scenarios (Liu et al., 2017). In this paper, we used GeoSOS-FLUS software (Liu et al., 2017) to facilitate the LUCC

\begin{tabular}{|c|c|c|c|c|c|c|c|c|c|}
\hline $\begin{array}{l}\text { Primary } \\
\text { classification }\end{array}$ & Secondary classification & Farmland & Forest & Grassland & $\begin{array}{l}\text { Inland } \\
\text { freshwater }\end{array}$ & $\begin{array}{l}\text { Saltwater } \\
\text { wetland }\end{array}$ & Shallow water & $\begin{array}{l}\text { Human-made } \\
\text { wetland }\end{array}$ & Unused land \\
\hline \multirow[t]{2}{*}{ Provisioning services } & Food supply & 2181.78 & 719.99 & 938.17 & 1156.34 & 785.44 & 29998.44 & 37846.40 & 43.64 \\
\hline & Raw material supply & 850.90 & 6501.71 & 785.44 & 763.62 & 523.63 & 497.82 & 0.00 & 87.27 \\
\hline \multirow[t]{4}{*}{ Regulating services } & Air quality regulation & 1570.88 & 9425.30 & 3272.67 & 1112.71 & 5258.10 & 4111.60 & 0.00 & 130.91 \\
\hline & Climate regulation & 2116.33 & 8879.85 & 3403.58 & 4494.47 & 29563.15 & 5459.23 & 4505.28 & 283.63 \\
\hline & Regulation of water flows & 1679.97 & 8923.49 & 3316.31 & 40952.05 & 29323.15 & 739.02 & 0.00 & 152.72 \\
\hline & Waste treatment & 3032.68 & 3752.67 & 2879.95 & 32399.47 & 31417.67 & 0.00 & 0.00 & 567.26 \\
\hline \multirow[t]{2}{*}{ Supporting services } & Maintenance of soil & 3207.22 & 8770.76 & 4887.19 & 894.53 & 4341.75 & 0.00 & 0.00 & 370.90 \\
\hline & Fertility habitat services & 2225.42 & 9839.84 & 4079.93 & 7483.51 & 8050.78 & 1.40 & 5070.21 & 872.71 \\
\hline Cultural services & $\begin{array}{l}\text { Cultural \& amenity } \\
\text { services }\end{array}$ & 370.90 & 4538.11 & 1898.15 & 9687.11 & 10232.56 & 18652.27 & 47421.90 & 523.63 \\
\hline
\end{tabular}

Table 1

Ecosystem service value per unit area for different land use/cover types in the Bohai Rim coastal zone (yuan/hm $\left.{ }^{2}\right)(2015$ prices). 
multi-scenario simulation by coupling human and natural effects (available for free download at http://www.geosimulation.cn/flus. html). GeoSOS-FLUS is a powerful tool that can be used to make LUCC simulations more convenient and efficient and can be easily used for several purposes (Liang et al., 2018a). According to the current situation and characteristics of land use and social-economic development in the research area, three scenarios, including business-as-usual (BAU), socio-economic development (SED) and ecological protection priority (EPP), were established. Based on the probability matrix of land use transfer from 2005 to 2015 , the total land use area of the three scenarios in 2025 was calculated by the Markov mathematical method. Using GeoSOS-FLUS software, the land use adaptability probability was calculated based on the land use data and driving factors of LUCC (e.g., DEM, slope, temperature, precipitation, population density, distance to town, distance to traffic, distance to water system), and the spatial distribution data of LUCC under the BAU, SED and EPP scenarios were obtained by modifying the transfer probability matrix and the class transformation restriction matrix (Liang et al., 2018b).

\section{Results}

\subsection{Land use/cover change during 2000-2015}

\subsubsection{Temporal analysis of land use/cover change}

Based on the proportions of land use/cover types (Table 2), farmland was the predominant land use type in the Bohai Rim coastal zone in 2000, 2005, 2010 and 2015, accounting for 48.92\%, 48.68\%, $47.38 \%$ and $47.36 \%$, respectively, and its proportion has shown a continuous downward trend. Shallow water and forest accounted for a large proportion, but these types also appeared to experience a sustained slow decline. However, the proportion of built-up land showed a trend of continuous increase, from $8.48 \%$ in 2000 to $11.44 \%$ in 2015 . Furthermore, inland freshwater and saltwater wetlands accounted for a small proportion, and both showed a decreasing trend. Moreover, the proportion of grassland initially decreased and then increased, while salt pan and mariculture first increased and then decreased. The proportion of unused land was the smallest, at only approximately $1 \%$.

During 2000-2015, the largest net area change occurred in the built-up land type, resulting in a total increase of $5026.22 \mathrm{~km}^{2}$ (Table 2). The net area changes in farmland, shallow water and mariculture were larger, followed by those of saltwater wetlands, grasslands, inland freshwater, salt pan and unused land; finally, the net area change in forestland was the smallest. The change area of the land use/ cover types showed varying characteristics during different phases. In 2000-2015, the areas of grassland, inland freshwater and shallow water decreased significantly, while mariculture and salt pan increased most significantly at this stage. From 2005 to 2010, the area of farmland decreased the most. Similar to farmland, saltwater wetland decreased more during this stage, and built-up land had the highest significant increase. During 2010-2015, the area of shallow water decreased the most, while the area of grassland increased.

The change rates of the land use/cover types showed varying characteristics during different periods (Table 2). During 2000-2015, farmland, shallow water, grassland, inland freshwater and forest all showed stages of slow decline, while saltwater wetland and unused land decreased more rapidly. In 2000-2015, unused land decreased the fastest $(-3.08 \%)$, while mariculture increased the fastest $(6.84 \%)$. During 2005-2010, saltwater wetland decreased at the fastest rate $(-2.85 \%)$, and mariculture grew at the fastest rate (4.51\%). From 2010 to 2015 , unused land and shallow water decreased rapidly, with values of $1.82 \%$ and $0.53 \%$, respectively.

\subsubsection{Spatial patterns of land use/cover change}

The spatial distribution of land use/cover types in the Bohai Rim coastal zone exhibited an overall pattern of "shallow water $\rightarrow$ saltwater wetland $\rightarrow$ human-made wetland $\rightarrow$ terrestrial multi-type mixed region" from the sea to the land (Fig. 2). Shallow water was mainly distributed in the eastern region. Saltwater wetland, salt pan and mariculture were concentrated in the coastal zone. Grassland was mainly scattered in the Yellow River Delta, the Liao River Delta and the mountainous regions. Forestland was mainly located in the Liaodong Peninsula, Jiaodong Peninsula and the mountainous regions. Unused land was mainly concentrated in the coastal zone. Farmland was widely distributed across the entire region, while built-up land was scattered.

To analyse the spatial distribution characteristics of land use in this area, nine circular buffers were established at $20-\mathrm{km}$ intervals with the coastline as the baseline, and the area of each land use/cover type was calculated (Table A.1). The land use/cover type structure between land and sea has spatial differences based on the distance from the coastline. The areas of saltwater wetland, salt pan, mariculture, inland freshwater and unused land decreased significantly with increasing distance from the coastline, while forestland and grassland decreased slowly. There was no significant change in farmland or built-up land. Saltwater wetland, salt pan and mariculture were mainly concentrated within $20 \mathrm{~km}$ of the coastline, both accounting for more than $73 \%$.

During 2000-2015, the land use/cover structure changed

Table 2

Land use/cover patterns in the Bohai Rim coastal zone.

\begin{tabular}{|c|c|c|c|c|c|c|c|c|}
\hline \multirow[t]{2}{*}{ LUCC } & \multicolumn{2}{|l|}{ Area $/ \mathrm{km}^{2}$} & \multicolumn{2}{|c|}{ Proportion/\% } & \multicolumn{2}{|c|}{ Area change $/ \mathrm{km}^{2}$} & \multicolumn{2}{|c|}{ Dynamic rate of change/\% } \\
\hline & 2000 & 2005 & 2010 & 2015 & $2000-2005$ & $2005-2010$ & 2010-2015 & $2000-2015$ \\
\hline \multirow[t]{2}{*}{ Farmland } & 82974.99 & 82566.82 & 80374.27 & 80323.32 & -408.17 & -2192.55 & -50.95 & -2651.67 \\
\hline & 48.92 & 48.68 & 47.39 & 47.36 & -0.10 & -0.53 & -0.01 & -0.64 \\
\hline \multirow[t]{2}{*}{ Forestland } & 19629.01 & 19570.88 & 19532.07 & 19497.4 & -58.13 & -38.81 & -34.67 & -131.61 \\
\hline & 11.57 & 11.54 & 11.52 & 11.50 & -0.06 & -0.04 & -0.04 & -0.13 \\
\hline \multirow[t]{2}{*}{ Grassland } & 8552.52 & 7984.44 & 7704.77 & 8045.75 & -568.08 & -279.67 & 340.98 & -506.77 \\
\hline & 5.04 & 4.71 & 4.54 & 4.74 & -1.33 & -0.70 & 0.89 & -1.19 \\
\hline \multirow[t]{2}{*}{ Built-up land } & 14380.02 & 15804.75 & 18652.1 & 19406.24 & 1424.73 & 2847.35 & 754.14 & 5026.22 \\
\hline & 8.48 & 9.32 & 10.99 & 11.44 & 1.98 & 3.60 & 0.81 & 6.99 \\
\hline \multirow[t]{2}{*}{ Inland freshwater } & 5580.19 & 5208.05 & 5173.4 & 5109.84 & -372.14 & -34.65 & -63.56 & -470.35 \\
\hline & 3.29 & 3.07 & 3.05 & 3.01 & -1.33 & -0.13 & -0.25 & -1.69 \\
\hline \multirow[t]{2}{*}{ Saltwater wetland } & 3716.87 & 3419.73 & 2931.81 & 2939.91 & -297.14 & -487.92 & 8.10 & -776.96 \\
\hline & 2.19 & 2.01 & 1.73 & 1.73 & -1.60 & -2.85 & 0.06 & -4.18 \\
\hline \multirow[t]{2}{*}{ Shallow water } & 28820.65 & 28495.86 & 27912.78 & 27173.79 & -324.79 & -583.08 & -738.99 & -1646.86 \\
\hline & 16.99 & 16.80 & 16.46 & 16.02 & -0.23 & -0.41 & -0.53 & -1.14 \\
\hline \multirow[t]{2}{*}{ Human-made wetland } & 4238.57 & 5106.89 & 5771.96 & 5698.66 & 868.32 & 665.07 & -73.30 & 1460.09 \\
\hline & 2.50 & 3.01 & 3.40 & 3.36 & 4.10 & 2.60 & -0.25 & 6.89 \\
\hline \multirow[t]{2}{*}{ Unused land } & 1720.86 & 1456.26 & 1560.52 & 1418.77 & -264.60 & 104.26 & -141.75 & -302.09 \\
\hline & 1.02 & 0.86 & 0.92 & 0.84 & -3.08 & 1.43 & -1.82 & -3.51 \\
\hline
\end{tabular}




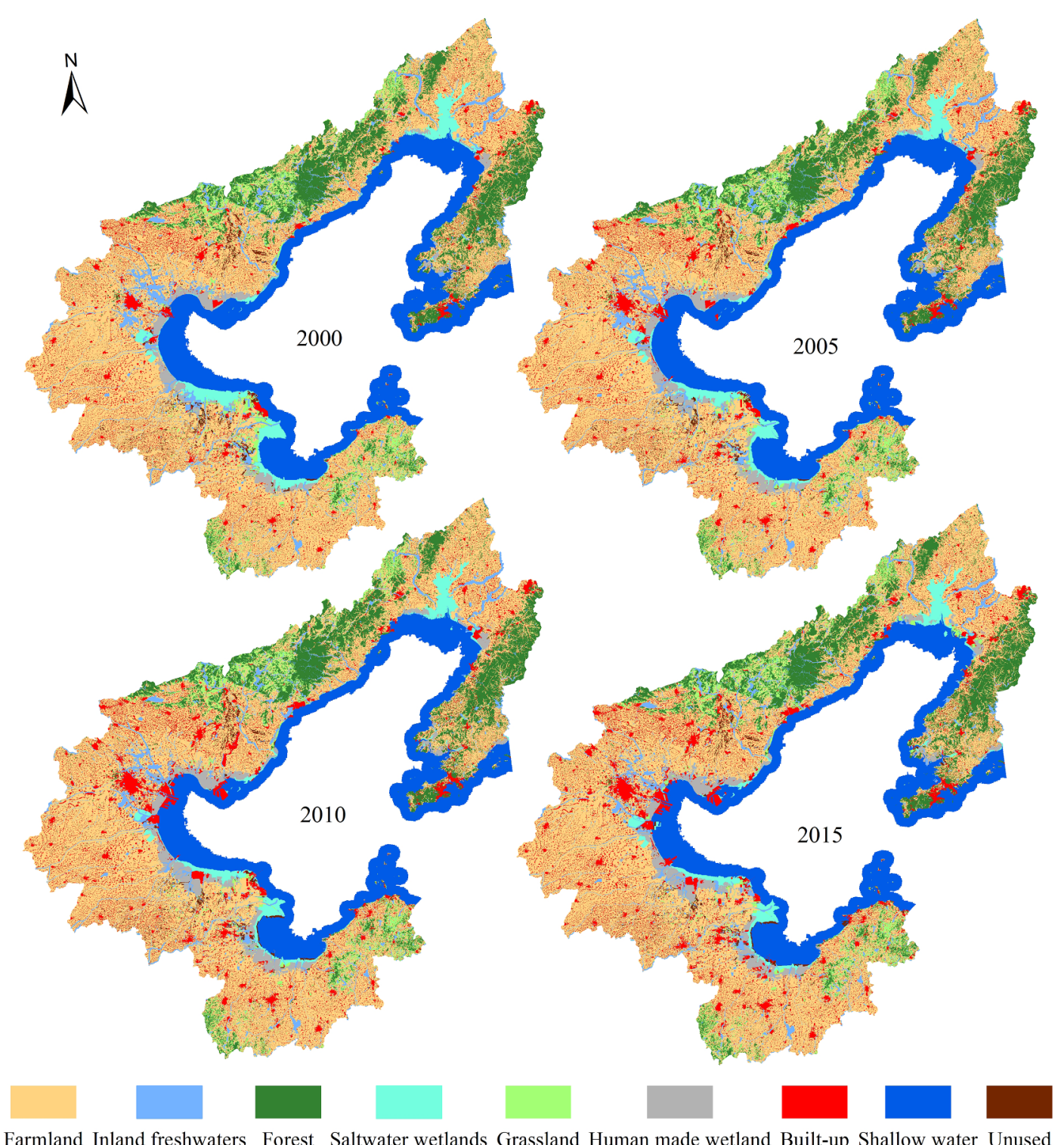

Fig. 2. Spatial distribution of land use/cover types in the Bohai Rim coastal zone.

significantly within $20 \mathrm{~km}$ of the coastline. Within the range of $0-20 \mathrm{~km}$ from the coastline, the areas of built-up land and mariculture increased significantly, increasing by $1473.95 \mathrm{~km}^{2}$ and $719.55 \mathrm{~km}^{2}$, respectively. However, the area of saltwater wetland decreased the most, reaching $1092.78 \mathrm{~km}^{2}$, and farmland and grassland decreased significantly, with reductions of $628.79 \mathrm{~km}^{2}$ and $373.07 \mathrm{~km}^{2}$, respectively. Within the range of $-20-0 \mathrm{~km}$ from the coastline, the area of shallow water decreased the most, reaching $1546.73 \mathrm{~km}^{2}$. However, the areas of built-up land, saltwater wetland, mariculture, grassland and inland freshwater all showed trends of substantial increases. These changes were mainly caused by the high-intensity development activities of humans as well as the estuary delta land-building activities.

\subsubsection{Transformation patterns of land use/cover types}

The total conversion area of land use/cover types in the Bohai Rim coastal zone reached $12330.13 \mathrm{~km}^{2}$ during of 2000-2015 (Fig. 3, Table A.2). The transformed land use types were mainly farmland, shallow water, inland freshwater, saltwater wetland and grassland, which accounted for $33.83 \%, 13.45 \%, 11.63 \%, 10.73 \%$ and $10.28 \%$ of the total transformed area, respectively; these land use types were mainly converted into built-up land, salt pan and mariculture.
Built-up land increased rapidly by $34.95 \%$, mainly occupying farmland $\left(3188.39 \mathrm{~km}^{2}\right)$ and shallow water $\left(701.21 \mathrm{~km}^{2}\right)$, which were converted into city, rural settlement and isolated industrial mining. Saltwater wetland was reclaimed within a large area but declined by $1322.96 \mathrm{~km}^{2}$, and this area mainly converted into mariculture, salt pan and built-up land. The newly formed area of saltwater wetland was $546 \mathrm{~km}^{2}$, and this change was mainly caused by land formation in the estuary delta. As a result of port construction and large-scale reclamation, the shallow water was transformed into built-up land $\left(701.21 \mathrm{~km}^{2}\right)$ and mariculture $\left(240.77 \mathrm{~km}^{2}\right)$, and the shallow water was transformed into saltwater wetland $\left(335.85 \mathrm{~km}^{2}\right)$ as a result of estuary land formation. The transformation of unused land mainly entailed conversions into farmland, built-up land, mariculture and salt pan. Grassland was typically converted into farmland, built-up land, mariculture and salt pan, while the transformation of forestland was the lowest. Thus, it can be seen that human activities represented the most important driving factors for the transformations of land use/cover types in the Bohai Rim coastal zone. 


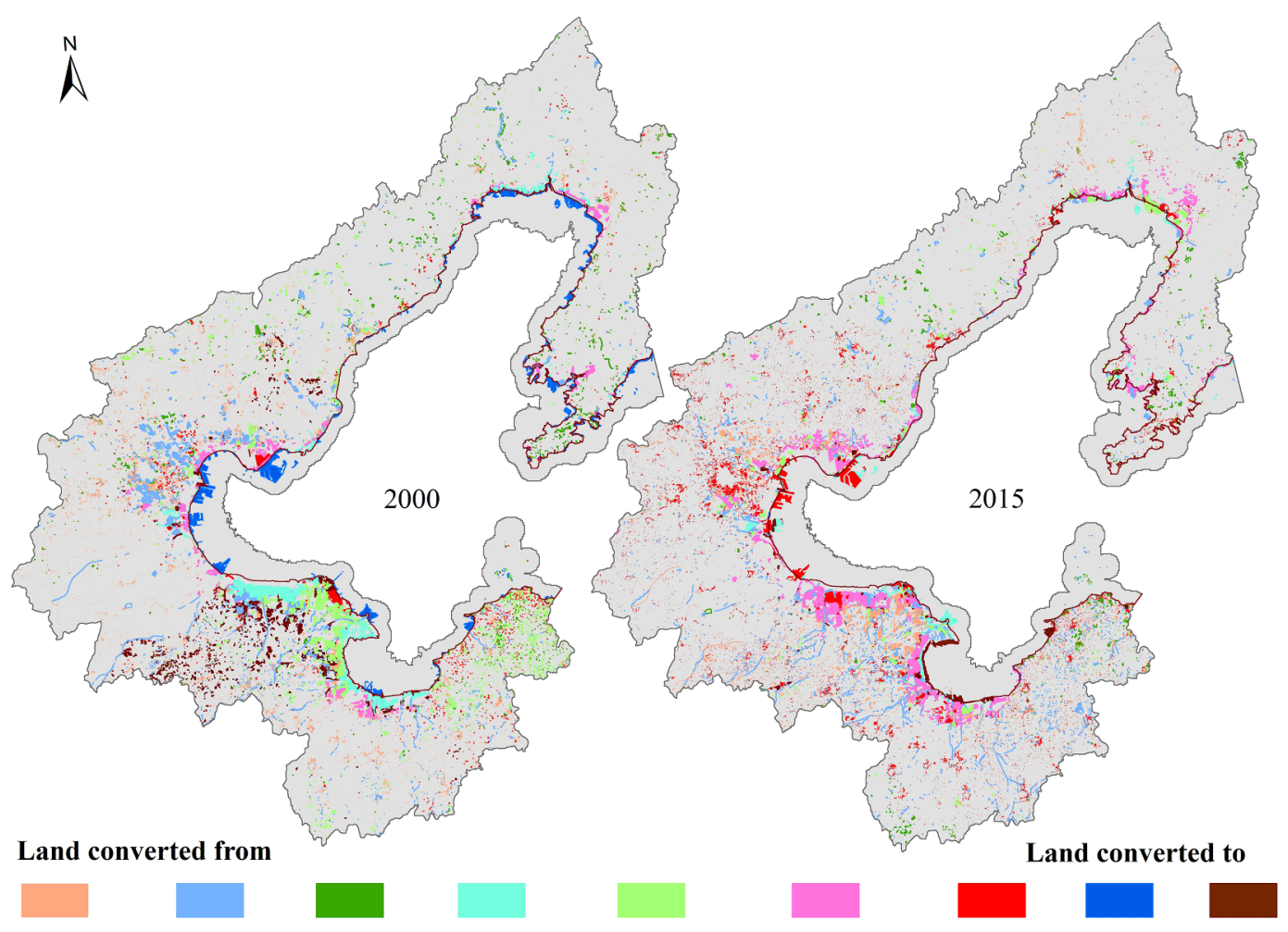

Farmland Inland freshwaters Forest Saltwater wetlands Grassland Human made wetland Built-up Shallow water Unused

Fig. 3. Transformation distribution of land use/cover types in the Bohai Rim coastal zone.

\subsection{Changes in ecosystem service values during 2000-2015}

\subsubsection{Temporal patterns of ecosystem service values}

With the high-speed development of industrialization and urbanization in the Bohai Rim coastal zone, the expansion of urban and rural construction land; the construction related to industry, mining and transportation; and the expansion of salt pan and aquaculture areas resulted in the occupation of tidal flats, estuary delta wetlands, cultivated land, forestland and grassland, representing the primary drivers of the reductions in ESVs. The ESVs for each land use category and the total value for each study year are shown in Table 3. During 2000-2015, the total ESVs showed a trend of continuous decline, and the losses in the ESVs of shallow water and saltwater wetlands were significant. From 2000 to 2015, the total ESVs decreased by $3.80 \%$, from 581.06 billion yuan to 558.97 billion yuan. The value of ecosystem services provided by different land types was different. Shallow water contributed most, at more than $28 \%$ of the total ESV, followed by the contributions of farmland and forestland, which accounted for more than $24 \%$ and $20 \%$, respectively. In contrast to the ESVs of salt pan and mariculture, those of all other land use/cover types decreased. The ESVs of shallow water and saltwater wetlands decreased significantly by 9.79 billion yuan and 9.28 billion yuan, respectively, followed by those of inland freshwater and farmland, which decreased by 4.65 billion yuan and 4.57 billion yuan, respectively. The ESVs of grassland and forestland decreased slightly, by 1.29 billion yuan and 807 million yuan, respectively, while that of unused land was the lowest, reaching
93 million yuan. In contrast, the ESV of mariculture and salt pan increased by 6.88 billion yuan and 1.52 billion yuan, respectively. The rate of decrease was greatest for saltwater wetlands (20.90\%), followed by that of unused land (17.78\%), while the rate of increase was largest for mariculture $(60.00 \%)$.

\subsubsection{Spatial change in ecosystem service value}

The spatial distribution of the ESV in the Bohai Rim coastal zone showed some regularity from 2000 to 2015 (Fig. 4); specifically, there were obvious characteristics of a land and sea gradient change, and the value of ecological service per unit area decreased gradually with the distance from the coastline (Fig. 5). The high-value areas of ecosystem services were distributed in patches or islands, mainly in the coastal wetlands of the Liaohe River Delta, Yellow River Delta and Laizhou Bay, which were less disturbed by human activities, while the low-value areas were mainly concentrated in high-intensity development zones, such as those of urban construction, industrial and mining transportation, aquaculture and reclamation.

From 2000 to 2015, the hotspots of ESV increasing and decreasing both could be found in the Bohai Rim coastal zone. Overall, the areas with declines were more widely distributed, while the areas with increases were small and scattered (Fig. 6). The ESV in the coastal zone changed more than that in the inland area. Within the range of $0-20 \mathrm{~km}$ from the coastline, the decline in the ESV per unit area was most significant. This area is mainly the concentrated area of saltwater wetlands, which are caused by large-scale reclamation activities and lead to

Table 3

Ecosystem service values of different land use/cover types ( $10^{8}$ yuan).

\begin{tabular}{|c|c|c|c|c|c|c|c|c|c|}
\hline LUCC & Farmland & Forestland & Grassland & Inland freshwater & Saltwater wetland & Shallow water & Human-made wetland & Unused land & Total \\
\hline 2000 & 1430.16 & 1204.27 & 217.76 & 552.13 & 444.15 & 1713.67 & 402.00 & 5.22 & 5969.36 \\
\hline 2005 & 1423.13 & 1200.71 & 203.29 & 515.30 & 408.64 & 1694.36 & 484.36 & 4.42 & 5934.21 \\
\hline 2010 & 1385.34 & 1198.33 & 196.17 & 511.88 & 350.34 & 1659.69 & 547.43 & 4.73 & 5853.91 \\
\hline 2015 & 1384.46 & 1196.20 & 204.86 & 505.59 & 351.31 & 1615.75 & 540.48 & 4.30 & 5802.94 \\
\hline
\end{tabular}




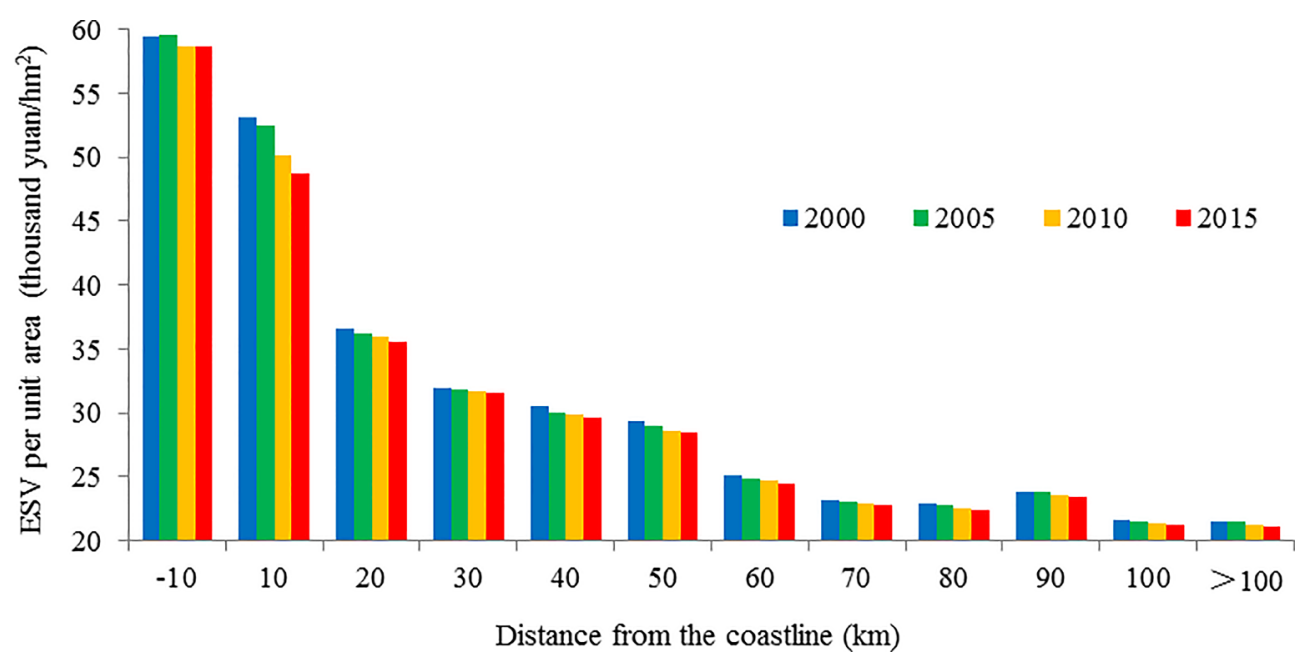

Fig. 4. Variation in sea-land gradient of ESV per unit area in the Bohai Rim coastal zone.

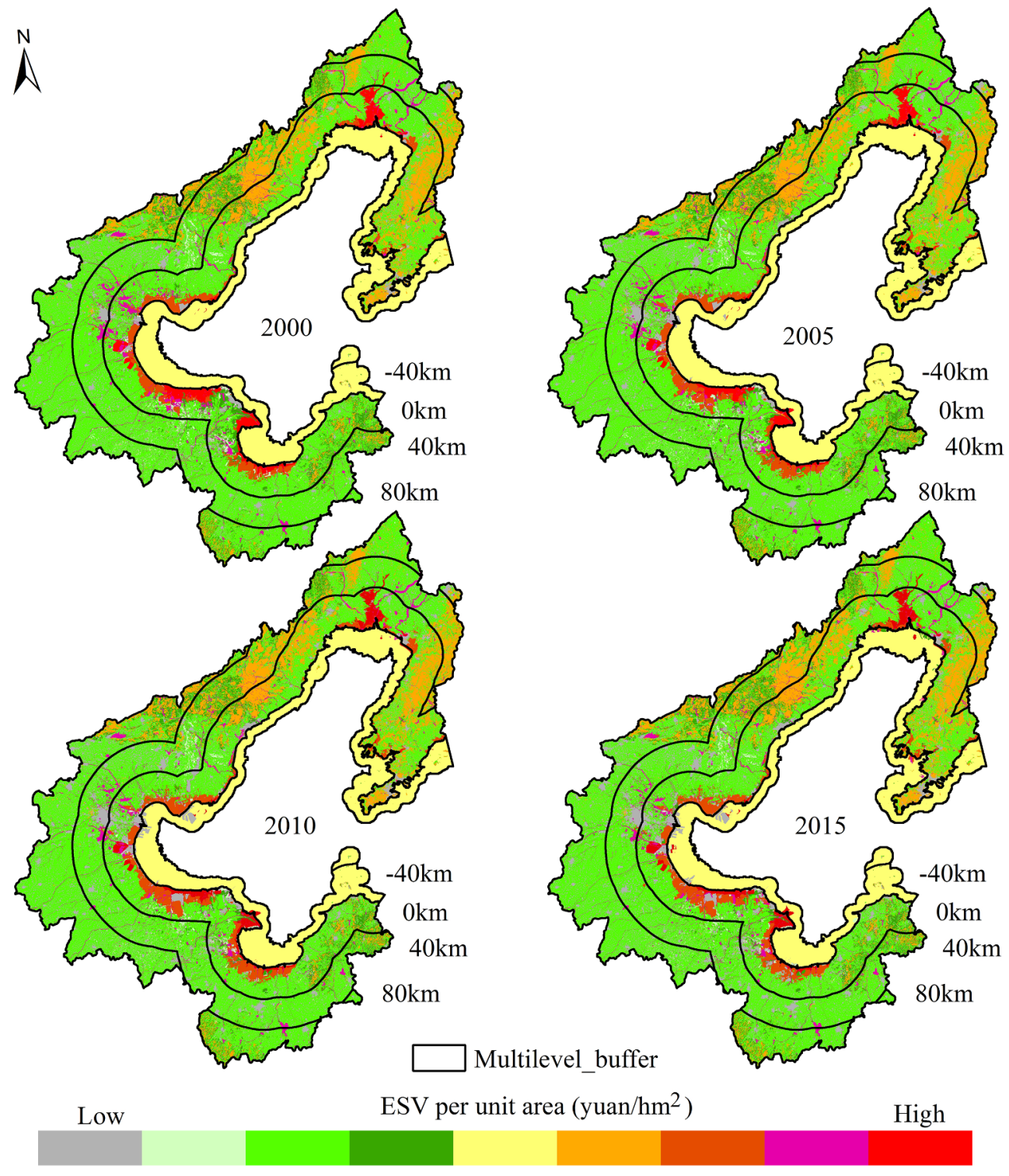

Fig. 5. Spatial distribution of ESV in the Bohai Rim coastal zone. 


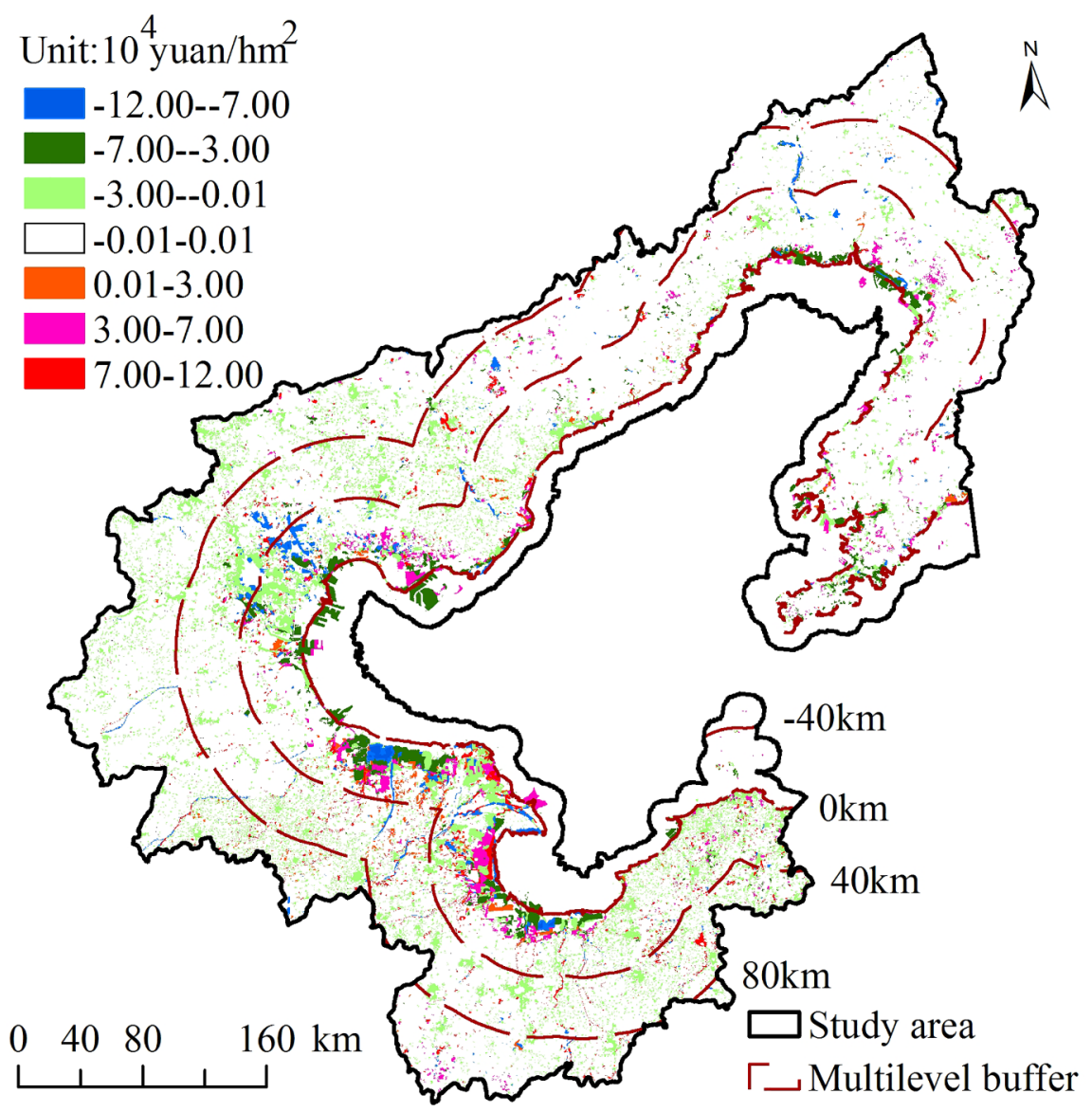

Fig. 6. Spatial change in the distribution of ESV in the Bohai Rim coastal zone from 2000 to 2015.

the loss of saltwater wetlands. The areas with the large increases in the ESVs are mainly concentrated in areas with improved ecological environments and newly developed wetland areas, especially in the newly developed Yellow River Delta.

\subsubsection{Changes in different ecosystem service values}

The value of regulating services accounted for the highest proportion, with more than $42 \%$ in all periods, followed by the value of provisioning services and supporting services, which accounted for more than $25 \%$ and $17 \%$, respectively, while cultural services contributed the least to the total ESV (Table 4). During all periods, regulating services and cultural services generally showed a decreasing trend, while provisioning services showed an initial increasing trend followed by a decreasing trend. However, supporting services initially decreased and then increased slightly. From 2000 to 2015, the regulating services, cultural services and supporting services decreased by 15.20 billion yuan, 3.85 billion yuan and 2.51 billion yuan, respectively, while the provisioning services declined slightly by 526 million yuan.

In terms of the ecosystem service sub-types, the food supply contributed most to the total ESV, followed by the cultural and amenity services, regulation of water flows, climate regulation, waste treatment, fertility habitat services, maintenance of soil and air quality regulation; in contrast, the raw material supply contributed the least. The value of food supply and raw material supply first increased and then decreased. In contrast to the ESVs of food supply and raw material supply, those of all other ecosystem service sub-types decreased during all periods.

Table 4

Values of different ecosystem services in the Bohai Rim coastal zone ( $10^{8}$ yuan).

\begin{tabular}{|c|c|c|c|c|c|}
\hline Primary classification & Secondary classification & 2000 & 2005 & 2010 & 2015 \\
\hline \multirow[t]{3}{*}{ Provisioning services } & Food supply & 1237.63 & 1258.6 & 1260.79 & 1235.96 \\
\hline & Raw material supply & 225.65 & 223.85 & 220.95 & 220.53 \\
\hline & Toal & 1463.28 & 1482.45 & 1481.74 & 1456.49 \\
\hline \multirow[t]{5}{*}{ Regulating services } & Air quality regulation & 487.82 & 481.42 & 471.71 & 469.34 \\
\hline & Climate regulation & 690.90 & 679.19 & 658.52 & 654.81 \\
\hline & Regulation of water flows & 701.99 & 674.67 & 653.57 & 651.37 \\
\hline & Waste treatment & 648.48 & 623.84 & 599.85 & 598.66 \\
\hline & Toal & 2529.19 & 2459.12 & 2383.65 & 2374.18 \\
\hline \multirow[t]{3}{*}{ Supporting services } & Maintenance of soil & 501.85 & 495.53 & 484.68 & 485.80 \\
\hline & Fertility habitat services & 507.41 & 502.61 & 495.48 & 495.51 \\
\hline & Toal & 1009.26 & 998.14 & 980.16 & 981.31 \\
\hline \multirow[t]{2}{*}{ Cultural services } & Cultural \& amenity services & 967.65 & 994.49 & 1008.36 & 990.96 \\
\hline & Toal & 967.65 & 994.49 & 1008.36 & 990.96 \\
\hline
\end{tabular}


Table 5

Transfer matrix of ecosystem service value changes caused by land use conversion in the Bohai Rim coastal zone ( $10^{6}$ yuan).

\begin{tabular}{|c|c|c|c|c|c|c|c|c|c|}
\hline LUCC & Farmland & Forestland & Grassland & Built-up land & Inland freshwater & Saltwater wetland & Shallow water & Human-made wetland & Unused \\
\hline Farmland & 0.00 & 2.38 & 0.54 & -54.96 & 32.08 & 0.50 & 0.00 & 34.49 & -0.30 \\
\hline Forestland & -3.44 & 0.00 & -0.73 & -8.61 & 1.02 & 0.04 & 0.00 & 0.18 & -0.09 \\
\hline Grassland & -3.85 & 2.23 & 0.00 & -6.08 & 8.70 & 7.22 & 0.00 & 18.83 & -0.73 \\
\hline Built-up land & 1.15 & 0.27 & 0.53 & 0.00 & 4.18 & 0.91 & 0.02 & 13.26 & 0.02 \\
\hline Inland freshwater & -44.69 & -0.58 & -10.04 & -23.30 & 0.00 & 1.55 & -0.01 & -1.63 & -2.46 \\
\hline Saltwater wetland & -1.91 & -0.10 & -10.45 & -29.18 & -3.00 & 0.00 & -0.62 & -15.05 & -21.02 \\
\hline Shallow water & -0.08 & 0.00 & -4.81 & -41.69 & 5.27 & 20.17 & 0.00 & 8.56 & -5.75 \\
\hline Human-made wetland & -3.86 & -0.01 & -16.41 & -39.40 & 0.20 & 0.51 & -0.01 & 0.00 & -4.95 \\
\hline Unused land & 4.12 & 0.18 & 0.65 & -0.45 & 5.38 & 2.79 & 0.00 & 15.88 & 0.00 \\
\hline
\end{tabular}

3.2.4. Impacts of land use/cover change conversions on ecosystem service value

Over the last several decades, the Bohai Rim coastal area has experienced profound LUCCs primarily due to intensive development activities, such as urban sprawl and the construction of manufacturing, mines and ports. These changes have significant impacts on the values of ecosystem services. Our study investigated the changes in ecosystem services in response to LUCCs (Table 5).

During 2000-2015, the main reason for the decrease in the value of ecosystem services was that saltwater wetland and inland freshwater were encroached, resulting in losses of 10.42 billion yuan and 9.60 billion yuan, respectively. The conversions from saltwater wetland to built-up land and unused land have resulted in an ESV loss of 2.92 billion yuan and 2.10 billion yuan, respectively. The ESV losses that resulted from conversions from inland freshwater to farmland and builtup land were considerable, with values of 4.47 billion yuan and 2.33 billion yuan, respectively. Additionally, the conversion of salt pan and mariculture to built-up land led to an ESV loss of 2.38 billion yuan. As a result of social and economic factors, the expansion of built-up land (such as urban expansion, industry and mining traffic construction) and farmland reclamation have caused large losses in ESVs, with values of 18.81 billion yuan and 5.07 billion yuan, respectively. Human development activities (built-up land) in shallow water have caused a total ESV loss of 4.17 billion yuan, while the land-building activities (saltwater wetland) in the Yellow River estuary and Liaohe River estuary increased the ESV by 2.02 billion yuan. The changes in the ESVs in the Bohai Rim coastal zone are mainly due to a decrease in saltwater wetland area and a sharp increase in built-up land area.

\subsection{Future changes in land use/cover and ecosystem service value under multi-scenario simulation}

\subsubsection{Land use/cover change in 2025}

Under the different scenarios (BAU, SED and EPP), the spatial patterns of land use/cover in Bohai Rim coastal zone were basically consistent, but there were differences in local areas (Fig. 7). Compared with 2015 , the area of each land use type was considerably different in 2025 , and the degree of overall land use fragmentation was more significant (Table 6).

Under the BAU scenario, the areas of built-up land and mariculture increased by $1790.76 \mathrm{~km}^{2}$ and $398.09 \mathrm{~km}^{2}$, respectively. However, the areas of farmland, saltwater wetland and forestland decreased by $2148.84 \mathrm{~km}^{2}, 134.74 \mathrm{~km}^{2}$ and $72.49 \mathrm{~km}^{2}$, respectively. It can be seen that the increase in the area of built-up land mostly came from the occupation of farmland, while the other land use types changed only slightly. Under the SED scenario, to continuously meet the demands of rapid economic and social growth on land resources, cities and towns continued to expand, and built-up land increased by $5783.59 \mathrm{~km}^{2}$. Urban growth showed an extensional feature, that is, most of the increase was located in the periphery of the original cities and towns. Mariculture increased significantly, with a value of $1470.09 \mathrm{~km}^{2}$, while farmland declined sharply, with a total reduction of $5632.12 \mathrm{~km}^{2}$. In addition, the areas of shallow water, grassland, saltwater wetland, unused land and inland freshwater decreased more, while the areas of forestland changed only slightly. The development and utilization of land made the characteristics of artificialization and fragmentation of land use in coastal areas extremely significant. Under the EPP scenario, the area of built-up land increased the least among all scenarios, with an increase of only $1183.96 \mathrm{~km}^{2}$. The areas of saltwater wetland, forestland, inland freshwater, and grassland increased significantly, with a total increase of $1661.86 \mathrm{~km}^{2}$. The largest reduction was in the area of unused land, which declined by $860.74 \mathrm{~km}^{2}$. Additionally, shallow water and farmland declined by $875.24 \mathrm{~km}^{2}$ and $643.71 \mathrm{~km}^{2}$, respectively. Under the BAU and SED scenarios, the increase in construction land was highly coincident with the spatial position of the reduction in cultivated, which was typically located around the original towns, indicating that the urbanization process will seriously encroach on farmland.

\subsubsection{Changes in ecosystem service values in 2025}

The changes in ESVs in the Bohai Rim coastal zone under different scenarios in 2025 are shown in Table 7. The ESVs of the SED scenario and BAU scenario showed a downward trend, while they increased under the EPP scenario. Under the EPP scenario, regulating services and support services increased significantly, while they declined dramatically under the SED scenario.

According to the type of ecosystem service, compared with 2015, the values of the regulating services under the SED and BAU scenarios decreased significantly, with decreases of 10.71 billion yuan and 2.07 billion yuan, respectively. In contrast, the value of regulating services increased significantly in the EPP scenario, with an increase of 7.70 billion yuan. The value of provisioning services declined the most in the EPP scenario, reaching 4.09 billion yuan, while the value of provisioning services in the SED scenario increased significantly by 3.93 billion yuan. The value of cultural services decreased under the SED and EPP scenarios, while it increased slightly under the BAU scenario. In addition, the value of supporting services declined under both the SED and the BAU scenarios, with decreases of 2.97 billion yuan and 0.98 billion yuan, respectively.

The ESVs under different scenarios changed differently because of different purposes. Under the SED scenario, for the purpose of pursuing economic benefits, construction land, salt pan and mariculture increased rapidly, while ecological land was lost in large quantities, which eventually led to the loss of ESV in the region. Under the ecological protection mode, the purpose of protecting the ecological environment was to replace the one-sided pursuit of economic development and to some extent limit development activities and appropriately restore the damaged habitat, causing the ESV to increase significantly in the region. 


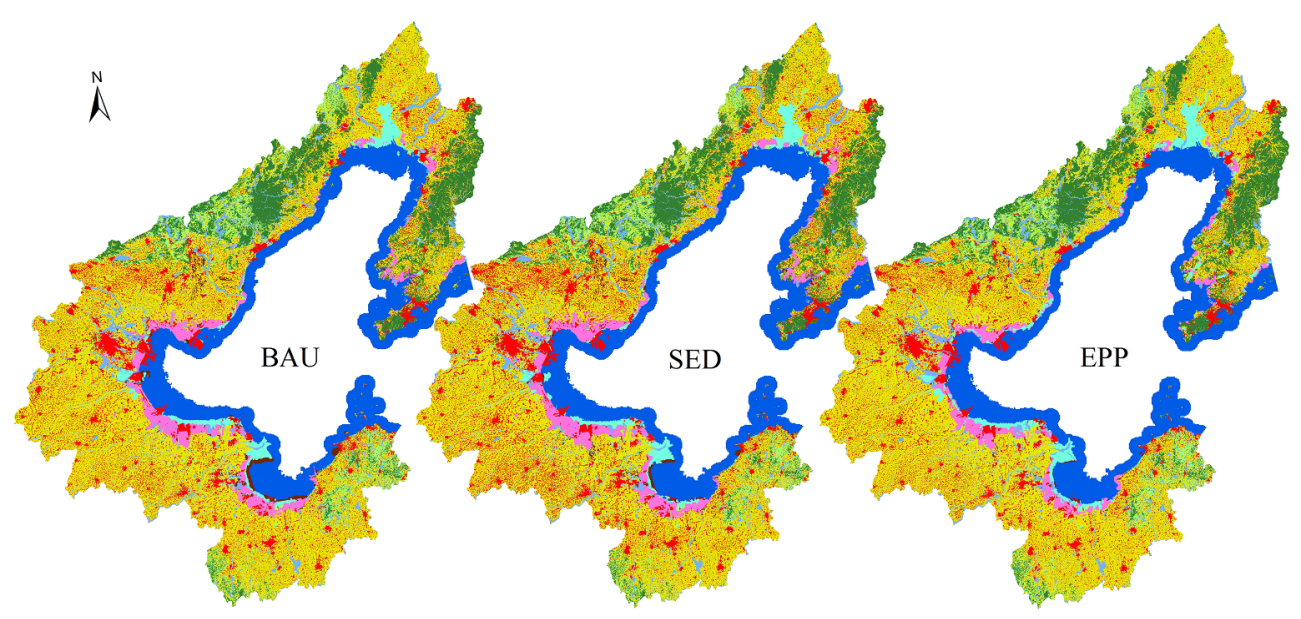

Fig. 7. Spatial distribution of land use/cover types in the Bohai Rim coastal zone under different scenarios

Table 6

Land use/cover change in the Bohai Rim coastal zone under different scenarios.

\begin{tabular}{lllll}
\hline \multirow{2}{*}{ LUCC } & \multicolumn{2}{l}{ Area/km $\mathrm{km}^{2}$} & & \\
\cline { 2 - 5 } & BAU & EPP & SED & 2015 \\
\hline Farmland & 78179.56 & 79798.52 & 74737.00 & 80323.32 \\
Forestland & 19424.88 & 19995.47 & 19438.78 & 19497.40 \\
Grassland & 8141.24 & 8253.20 & 7825.82 & 8045.75 \\
Built-up land & 21981.19 & 20973.64 & 24899.98 & 19406.24 \\
Inland freshwater & 5122.08 & 5329.92 & 5080.79 & 5109.84 \\
Saltwater wetland & 2591.31 & 3157.15 & 2562.71 & 2939.91 \\
Shallow water & 26679.43 & 26476.81 & 26760.69 & 27173.79 \\
Human-made wetland & 6122.15 & 5066.50 & 7088.67 & 5698.66 \\
Unused land & 1371.84 & 562.47 & 1219.24 & 1418.77 \\
\hline
\end{tabular}

Table 7

Ecosystem service values of the Bohai Rim coastal zone in 2025 under multiple scenarios $\left(10^{8}\right.$ yuan $)$.

\begin{tabular}{lllll}
\hline $\begin{array}{l}\text { Primary } \\
\text { classification }\end{array}$ & Secondary classification & BAU & SED & EPP \\
\hline \multirow{2}{*}{ Provisioning services } & Food supply & & & \\
& Raw material supply & 217.88 & 214.78 & 223.34 \\
& Total & 1450.13 & 1478.18 & 1414.26 \\
Regulating services & Air quality regulation & 461.74 & 455.55 & 472.29 \\
& Climate regulation & 638.90 & 634.39 & 659.35 \\
& Regulation of water flows & 637.35 & 628.15 & 670.36 \\
& Waste treatment & 581.58 & 567.96 & 613.00 \\
& Total & 2319.57 & 2286.05 & 2415.00 \\
Supporting services & Maintenance of soil & 477.24 & 464.56 & 490.33 \\
& Fertility habitat services & 489.80 & 485.22 & 499.53 \\
& Total & 967.04 & 949.78 & 989.86 \\
Cultural services & Cultural \& amenity & 997.41 & 1042.18 & 954.35 \\
& services & & & \\
\multirow{2}{*}{ Total } & Total & 997.41 & 1042.18 & 954.35 \\
& & 5734.16 & 5756.18 & 5773.48 \\
\hline
\end{tabular}

\section{Discussion and conclusions}

\subsection{Discussion}

The impact of LUCCs on ecosystem services is very complex. LUCC leads to changes in ecosystem structure and function and will lead to changes in the ESV per unit area (Simmons et al., 2008; Wang et al., 2015). This paper ignores the influence of changes in ecosystem structure and function on the value of ecosystem services and does not consider correlations and heterogeneity among ecosystem service types, which would also have an impact on the results. The main limitation of this study is associated with the accuracy and confidence level of the analysed results, including the land-cover data accuracy and the ESV valuation method.

The LUCC data were obtained from the interpretation of 30-m resolution remote sensing images by Di Xianghong and Hou Xiyong (Di et al., 2015). The quality of ESVs partly depends on the accuracy of the LUCC classification. The higher resolution land use data provide more accurate results (Wang et al., 2018). There is a high total accuracy (both pros and pres) in the land use mapping in China's coastal zone. However, the classification accuracy of built-up land, freshwater wetlands and human-made saltwater wetlands is relatively low, while the accuracy of unused land represents the most serious type of misclassification; finally, the accuracies of farmland, built-up land, forestland, grassland and saltwater wetlands are also easily misclassified. These issues should be given more attention during the continuous updating of land use maps in the future (Hou et al., 2018). In addition, the LUCC datasets do not have a detailed classification. For example, there is no distinction between grassland, forestland and other land types in builtup land because of the limitation of remote sensing image resolution. Thus, to overcome these limitations, a more detailed land use/land cover classification and the generation of land use/cover datasets with high resolution are needed (Konarska et al., 2002; Arowolo et al., 2018).

The BTM (including basic value transfer, expert modified value transfer, and statistical value transfer) for ecosystem services plays a vital role (Costanza et al., 2014; Song and Deng, 2017). It is widely criticized because of its reliability, validity, and uncertainties. We still adopted this approach in our assessment of ecosystem services because of its quick assessment and the low cost associated with collecting the primary data needed to achieve our objectives (Troy and Wilson, 2006).

Several scholars have evaluated the ESV of the Bohai Rim coastal zone and the impacts of LUCC on the ESV (Suo et al, 2011; Miao and Liu, 2014; Zhang et al., 2015a,b). They pointed out that the decline of ESVs in the region was mainly due to the loss of coastal wetlands. In this study, when evaluating the value of ecological services, the BTM was used to supplement the ESV of shallow waters, making the analysis more complete. In addition, we predicted future spatiotemporal changes in LUCC and ESV through a multi-scenario simulation. We also examined spatiotemporal changes in LUCC and ESV along a land-sea gradient. This study will help decision makers better understand tradeoffs between ecosystem services caused by LUCC and provide a relevant scientific reference and support for ecosystem protection and integrated management in the Bohai Rim coastal zone.

\subsection{Conclusions}

This paper focuses on the impacts of LUCCs on ecosystem services in 
Table A.1

Area and proportion of land use/cover types in different buffer zones from 2000 to 2015 .

\begin{tabular}{|c|c|c|c|c|c|c|c|c|c|}
\hline \multirow[t]{2}{*}{2000 LUCC } & \multicolumn{9}{|c|}{ Area $/ \mathrm{km}^{2}$ Ratio/\% } \\
\hline & $-60 \sim-40$ & $-40 \sim-20$ & $-20 \sim 0$ & $0 \sim 20$ & $20 \sim 40$ & $40 \sim 60$ & $60 \sim 80$ & $80 \sim 100$ & $>100$ \\
\hline \multirow[t]{2}{*}{ Farmland } & 4.01 & 24.04 & 6.07 & 13602.96 & 15167.63 & 15314.34 & 15190.76 & 11642.89 & 12022.27 \\
\hline & 0.00 & 0.03 & 0.01 & 16.39 & 18.28 & 18.46 & 18.31 & 14.03 & 14.49 \\
\hline \multirow[t]{2}{*}{ Forest } & 2.17 & 39.60 & 18.40 & 3844.93 & 5475.79 & 4233.79 & 2579.89 & 1966.32 & 1468.13 \\
\hline & 0.01 & 0.20 & 0.09 & 19.59 & 27.90 & 21.57 & 13.14 & 10.02 & 7.48 \\
\hline \multirow[t]{2}{*}{ Grassland } & 0.00 & 11.70 & 3.10 & 1724.77 & 1830.11 & 1741.39 & 1222.93 & 1017.50 & 1001.03 \\
\hline & 0.00 & 0.14 & 0.04 & 20.16 & 21.40 & 20.36 & 14.30 & 11.90 & 11.70 \\
\hline \multirow[t]{2}{*}{ Built-up } & 2.66 & 10.77 & 4.13 & 2927.16 & 2313.99 & 2674.51 & 2556.53 & 1953.31 & 1936.96 \\
\hline & 0.02 & 0.07 & 0.03 & 20.36 & 16.09 & 18.60 & 17.78 & 13.58 & 13.47 \\
\hline \multirow[t]{2}{*}{ Inland freshwaters } & 0.00 & 0.11 & 0.47 & 1420.39 & 1420.86 & 1217.08 & 669.43 & 439.47 & 412.38 \\
\hline & 0.00 & 0.00 & 0.01 & 25.45 & 25.46 & 21.81 & 12.00 & 7.88 & 7.39 \\
\hline \multirow[t]{2}{*}{ Saltwater wetlands } & 0.10 & 8.00 & 9.92 & 3258.98 & 383.56 & 55.86 & 0.46 & 0.00 & 0.00 \\
\hline & 0.00 & 0.22 & 0.27 & 87.68 & 10.32 & 1.50 & 0.01 & 0.00 & 0.00 \\
\hline \multirow[t]{2}{*}{ Shallow water } & 590.86 & 10745.39 & 17480.09 & 4.31 & 0.00 & 0.00 & 0.00 & 0.00 & 0.00 \\
\hline & 2.05 & 37.29 & 60.65 & 0.01 & 0.00 & 0.00 & 0.00 & 0.00 & 0.00 \\
\hline \multirow[t]{2}{*}{ Human made wetland } & 0.00 & 0.00 & 0.00 & 4030.62 & 196.63 & 11.31 & 0.00 & 0.00 & 0.00 \\
\hline & 0.00 & 0.00 & 0.00 & 95.09 & 4.64 & 0.27 & 0.00 & 0.00 & 0.00 \\
\hline \multirow[t]{2}{*}{ Unused } & 0.00 & 0.17 & 0.19 & 492.94 & 456.62 & 337.71 & 226.64 & 123.92 & 82.67 \\
\hline & 0.00 & 0.01 & 0.01 & 28.65 & 26.53 & 19.63 & 13.17 & 7.20 & 4.80 \\
\hline \multirow[t]{2}{*}{2015 LUCC } & \multicolumn{9}{|c|}{ Area/km² Ratio/\% } \\
\hline & $-60 \sim-40$ & $-40 \sim-20$ & $-20 \sim 0$ & $0 \sim 20$ & $20 \sim 40$ & $40 \sim 60$ & $60 \sim 80$ & $80 \sim 100$ & $>100$ \\
\hline \multirow[t]{2}{*}{ Farmland } & 3.99 & 22.74 & 7.37 & 12974.17 & 14950.19 & 14794.42 & 14611.11 & 11229.81 & 11729.53 \\
\hline & 0.01 & 0.03 & 0.01 & 16.15 & 18.61 & 18.42 & 18.19 & 13.98 & 14.60 \\
\hline \multirow[t]{2}{*}{ Forest } & 2.16 & 40.50 & 19.60 & 3798.12 & 5433.64 & 4208.44 & 2556.28 & 1957.13 & 1481.52 \\
\hline & 0.01 & 0.21 & 0.10 & 19.48 & 27.87 & 21.58 & 13.11 & 10.04 & 7.60 \\
\hline \multirow[t]{2}{*}{ Grassland } & 0.00 & 10.27 & 143.22 & 1351.70 & 1646.02 & 1697.70 & 1214.50 & 1016.24 & 966.10 \\
\hline & 0.00 & 0.13 & 1.78 & 16.80 & 20.46 & 21.10 & 15.09 & 12.63 & 12.01 \\
\hline \multirow[t]{2}{*}{ Built-up } & 2.66 & 99.34 & 620.33 & 4401.11 & 2985.97 & 3386.21 & 3199.39 & 2407.57 & 2303.66 \\
\hline & 0.01 & 0.51 & 3.20 & 22.68 & 15.39 & 17.45 & 16.49 & 12.40 & 11.87 \\
\hline \multirow[t]{2}{*}{ Inland freshwaters } & 0.00 & 0.29 & 133.20 & 1194.86 & 1150.46 & 1128.67 & 681.62 & 431.02 & 389.71 \\
\hline & 0.00 & 0.01 & 2.61 & 23.38 & 22.51 & 22.09 & 13.34 & 8.43 & 7.63 \\
\hline \multirow[t]{2}{*}{ Saltwater wetlands } & 0.09 & 25.85 & 323.09 & 2166.19 & 369.76 & 54.48 & 0.45 & 0.00 & 0.00 \\
\hline & 0.00 & 0.88 & 10.99 & 73.68 & 12.58 & 1.85 & 0.02 & 0.00 & 0.00 \\
\hline \multirow[t]{2}{*}{ Shallow water } & 590.90 & 10638.00 & 15933.36 & 11.53 & 0.00 & 0.00 & 0.00 & 0.00 & 0.00 \\
\hline & 2.17 & 39.15 & 58.64 & 0.04 & 0.00 & 0.00 & 0.00 & 0.00 & 0.00 \\
\hline \multirow[t]{2}{*}{ Human made wetland } & 0.00 & 0.00 & 242.78 & 4951.44 & 451.49 & 33.97 & 0.00 & 16.48 & 2.51 \\
\hline & 0.00 & 0.00 & 4.26 & 86.89 & 7.92 & 0.60 & 0.00 & 0.29 & 0.04 \\
\hline \multirow[t]{2}{*}{ Unused } & 0.00 & 2.78 & 99.44 & 457.92 & 257.66 & 282.11 & 183.28 & 85.17 & 50.41 \\
\hline & 0.00 & 0.20 & 7.01 & 32.28 & 18.16 & 19.88 & 12.92 & 6.00 & 3.55 \\
\hline
\end{tabular}

the Bohai Rim coastal zone. The main conclusions are as follows.

Farmland was the predominant land use/cover type in the Bohai Rim coastal zone during the period of 2000-2015, and its proportion showed a decreasing trend. The areas of shallow water and forestland accounted for a large proportion, and both also exhibited sustained small declines. In contrast, the areas of built-up land and mariculture showed a trend of continuous increases. The land use/cover structure changed significantly within $20 \mathrm{~km}$ of the coastline because of the highintensity development activities of humans and the estuary delta landbuilding activities.

During 2000-2015, the total ESV of the Bohai Rim coastal zone decreased significantly by 22.09 billion yuan, which was a decline of
$3.80 \%$. The spatial distribution of ESVs showed some regularity, there were obvious characteristics of a land and sea gradient change, and the ESV per unit area decreased gradually with the distance from the coastline. Within the range of $0-20 \mathrm{~km}$ from the coastline, the ESV per unit area showed the most significant declined, and this decline was mainly due to the loss of coastal wetlands caused by large-scale reclamation activities.

Compared with 2015, the total ESVs under the SED scenario and BAU scenario in 2025 showed a declining trend, while they increased under the EPP scenario. Under the EPP scenario, regulating services and support services increased significantly, while they declined dramatically under the SED scenario. LUCC patterns were the main reason for

Table A.2

Conversion matrix of land use/cover change $\left(\mathrm{km}^{2}\right)$ in the Bohai Rim coastal zone from 2000 to 2015.

\begin{tabular}{|c|c|c|c|c|c|c|c|c|c|}
\hline LUCC & Farmland & Forest & Grassland & Built-up & Inland freshwaters & Saltwater wetlands & Shallow water & Human-made wetland & Unused \\
\hline Farmland & 78804.02 & 54 & 65.81 & 3188.39 & 392.67 & 4.90 & 0.08 & 444.35 & 20.77 \\
\hline Forest & 78.04 & 19355.41 & 20.24 & 140.37 & 27.19 & 0.64 & 0.07 & 5.50 & 1.55 \\
\hline Grassland & 467.88 & 62.21 & 7284.64 & 238.64 & 118.39 & 76.79 & 0.07 & 271.43 & 32.47 \\
\hline Built-up & 66.48 & 4.39 & 20.77 & 14093.07 & 42.25 & 7.58 & 0.26 & 139.83 & 5.39 \\
\hline Inland freshwaters & 546.9 & 15.50 & 136.59 & 235.53 & 4146.16 & 75.43 & 0.37 & 398.02 & 25.69 \\
\hline Saltwater wetlands & 18.71 & 1.77 & 111.09 & 244.17 & 146.00 & 2393.91 & 10.40 & 610.35 & 180.47 \\
\hline Shallow water & 1.78 & 0.93 & 141.34 & 701.21 & 133.43 & 335.85 & 27162.14 & 242.03 & 101.94 \\
\hline Human-made wetland & 49.69 & 0.18 & 236.50 & 415.38 & 47.62 & 20.84 & 0.34 & 3414.15 & 53.87 \\
\hline Unused & 289.82 & 3.01 & 28.77 & 149.48 & 56.13 & 23.97 & 0.06 & 173.00 & 996.62 \\
\hline
\end{tabular}


the decrease in ESV. For example, urban expansion, the construction of industrial and mining transportation and the development of salt pans and aquaculture ponds have led to the occupation of tidal flats, coastal wetlands, cultivated land, forest and grassland.

\section{CRediT authorship contribution statement}

Yubin Liu: Writing - original draft. Xiyong Hou: Writing - review \& editing. Xiaowei Li: Data curation. Baiyuan Song: Software. Chao Wang: Formal analysis.

\section{Declaration of Competing Interest}

The authors declare that they have no known competing financial interests or personal relationships that could have appeared to influence the work reported in this paper.

\section{Acknowledgments}

The work was supported by the Strategic Priority Research Program of the Chinese Academy of Sciences [grant numbers XDA19060205]; the National Natural Science Foundation of China [grant numbers 31461143032]; and Science and Technology Service Network Initiative (STS) Project of the Chinese Academy of Sciences [grant numbers KFJSTS-ZDTP-023]. We are grateful to Dr. Di Xianghong and Wu Li for their contributions during LUCC data downloading and processing. We also thank the anonymous reviewers for their precise and insightful comments.

\section{References}

Arowolo, A.O., Deng, X., Olatunji, O.A., Obayelu, A.E., 2018. Assessing changes in the value of ecosystem services in response to land-use/land-cover dynamics in Nigeria. Sci. Total Environ. 636, 597-609.

Boone, R.B., Conant, R.T., Sircely, J., Thornton, P.K., Herrero, M., 2018. Climate change impacts on selected global rangeland ecosystem services. Glob. Change Biol. 24, 1382-1393.

Bussmann, R.W., 1996. Destruction and management of Mount Kenya's forests. Ambio 25, 314-317.

Cohen, B., 2006. Urbanization in developing countries: current trends, future projections, and key challenges for sustainability. Technol. Soc. 28, 63-80.

Costanza, R., d'Arge, R., de Groot, R., Farber, S., Grasso, M., Hannon, B., Limburg, K., Naeem, S., O'Neill, R.V., Paruelo, J., Raskin, R.G., Sutton, P., van den Belt, M., 1997. The value of the world's ecosystem services and natural capital. Nature 387, 253-260.

Costanza, R., de Groot, R., Sutton, P., van der Ploeg, S., Anderson, S.J., Kubiszewski, I., Farber, S., Turner, R.K., 2014. Changes in the global value of ecosystem services. Global Environ. Change 26, 152-158.

Cui, L.J., 2005. Service function and value of wetland eco-system. J. Sichuan For. Sci. Technol. 26, 41-42.

Dadashpoor, H., Azizi, P., Moghadasi, M., 2019. Land use change, urbanization, and change in landscape pattern in a metropolitan area. Sci. Total Environ. 655, 707-719.

de Araujo Barbosa, Caio C., Atkinson, Peter M., Dearing, John A., 2016. Extravagance in the commons: Resource exploitation and the frontiers of ecosystem service depletion in the Amazon estuary. Sci. Total Environ. 550, 6-16. https://doi.org/10.1016/j. scitotenv.2016.01.072.

de Groot, R., Brander, L., van der Ploeg, S., Costanza, R., Bernard, F., Braat, L., Christie, M., Crossman, N., Ghermandi, A., Hein, L., Hussain, S., Kumar, P., McVittie, A., Portela, R., Rodriguez, L.C., ten Brink, P., van Beukering, P., 2012. Global estimates of the value of ecosystems and their services in monetary units. Ecosyst. Serv. 1, $50-61$.

Di, X.H., Hou, X.Y., Wu, L., 2014. Land use classification system for China's coastal zone based on remote sensing. Resour. Sci. 36, 463-472.

Di, X., Hou, X., Wang, Y., Wu, L., 2015. Spatial-temporal characteristics of land use intensity of coastal zone in China during 2000-2010. Chin. Geogr. Sci. 25, 51-61.

Dittman, D.E., Chalupnicki, M.A., Johnson, J.H., Snyder, J., 2015. Reintroduction of Lake Sturgeon (Acipenser fulvescens) into the St. Regis River, NY: post-release assessment of habitat use and growth. Northeastern Naturalist 22, 704-716.

Escobedo, F.J., Kroeger, T., Wagner, J.E., 2011. Urban forests and pollution mitigation: analyzing ecosystem services and disservices. Environ. Pollut. 159, 2078-2087.

Gai, M., Nie, C., Ke, L.N., 2018. Carrying capacity and coordinated development of ERE system in the coastal area of Bohai Sea. Econ. Geogr. 38, 163-172.
Guo, L.Y., Wang, D.L., Qiu, J.J., 2009. Regional landscape pattern changes surrounding the Bohai Bay in China. Resour. Sci. 31, 2144-2149.

Hou, X.Y., Di, X.H., Hou, W., Wu, L., Liu, J., Wang, J.H., Su, H.F., Lu, X., Ying, L.L., Yu, X.Y., Wu, T., Zhu, M.M., Han, L., Li, M.J., 2018. Accuracy evaluation of land use mapping using remote sensing techniques in coastal zone of China. J. Geo-Inf. Sci. 20, $1478-1488$.

Konarska, K.M., Sutton, P.C., Castellon, M., 2002. Evaluating scale dependence of ecosystem service valuation_ a comparison of NOAA-AVHRR and Landsat TM datasets. Ecol. Econ. 491-507.

Li, L., 2011. Research on Ecosystem Services Evaluation of the Modern Yellow Delta Wetland Based on 3s Technology. Shandong University of Science and Technology.

Li, B.J., Chen, D.X., Wu, S.H., Zhou, S.Z., Wang, T., Chen, H., 2016. Spatio-temporal assessment of urbanization impacts on ecosystem services: case study of Nanjing City, China. Ecol. Ind. 71, 416-427.

Li, Y., Feng, Y., Guo, X., Peng, F., 2017. Changes in coastal city ecosystem service values based on land use-A case study of Yingkou, China. Land Use Policy 65, 287-293.

Li, Y.F., Zhan, J.Y., Liu, Y., Zhang, F., Zhang, M.L., 2018. Response of ecosystem services to land use and cover change: A case study in Chengdu City. Resour. Conserv. Recycl. $132,291-300$.

Liang, X., Liu, X.P., Li, X., Chen, Y.M., Tian, H., Yao, Y., 2018b. Delineating multi-scenario urban growth boundaries with a CA-based FLUS model and morphological method. Landscape Urban Plann. 177, 47-63.

Liang, X., Liu, X., Li, D., Zhao, H., Chen, G., 2018a. Urban growth simulation by incorporating planning policies into a CA-based future land-use simulation model. Int J. Geogr. Information Sci. 32, 2294-2316.

Liu, X.P., Liang, X., Li, X., Xu, X.C., Ou, J.P., Chen, Y.M., Li, S.Y., Wang, S.J., Pei, F.S., 2017. A future land use simulation model (FLUS) for simulating multiple land use scenarios by coupling human and natural effects. Landscape Urban Plann. 168, 94-116.

Mei, H., Yin, Y.J., 2009. Studies on marine oil spills and their ecological damage. Oceanic Coastal Sea Res. 8, 312-316.

Miao, H.N., Liu, B.Q., 2014. Analysis on the value change of ecosystem services in coastal areas of the Bohai Bay in recent 20 years based on the remote sensing. Mar. Sci. Bull. $33,121-125$.

Millennium Ecosystem Assessment, 2005. Ecosystems and Human Well-being: Synthesis. Island Press, Washington DC.

Odgaard, M.V., Turner, K.G., Bøcher, P.K., Svenning, J.-C., Dalgaard, T., 2017. A multicriteria, ecosystem-service value method used to assess catchment suitability for potential wetland reconstruction in Denmark. Ecol. Ind. 77, 151-165.

Roy, P.S., Roy, A., Murtugudde, R., Sengupta, D.J.J., 2010. Land use and land cover change in India: a remote sensing \& GIS prespective. 90, 489-502.

Simmons, J.A., Currie, W.S., Eshleman, K.N., Kuers, K., Monteleone, S., Negley, T.L. Pohlad, B.R., Thomas, C.L., 2008. Forest to reclaimed mine land use change leads to altered ecosystem structure and function. Ecol. Appl. 18, 104-118.

Song, X.P., 2018. Global Estimates of ecosystem service value and change: taking into account uncertainties in satellite-based land cover data. Ecol. Econ. 143, 227-235.

Song, W., Deng, X., 2017. Land-use/land-cover change and ecosystem service provision in China. Sci. Total Environ. 576, 705-719.

Su, H.F., Hou, X.Y., Di, X.H., 2016. Spatio-temporal characteristics and scenario analysis of land-use change in the Beibu Gulf Economic Rim coastal area, China. Marine Science 40, 107-116.

Suo, A.N., Yu, Y.H., Jiang, N., 2011. Response of ecosystem service value to land use change in coastal zone of Bohai Sea in last 30 years. Adv. Mater. Res. 347-353, 3963-3967.

Troy, A., Wilson, M.A., 2006. Mapping ecosystem services: Practical challenges and opportunities in linking GIS and value transfer. Ecol. Econ. 60, 435-449.

Wang, Y., Dai, E., Yin, L., Ma, L., 2018. Land use/land cover change and the effects on ecosystem services in the Hengduan Mountain region, China. Ecosyst. Serv. 34, 55-67.

Wang, S.R., Meng, W., Jin, X.C., Zheng, B.H., Zhang, L., Xi, H.Y., 2015. Ecological security problems of the major key lakes in China. Environmental Earth Sciences 74, 3825-3837.

Xie, G.D., Zhang, C.X., Zhang, L.M., Chen, W.H., Li, S.M., 2015. Improvement of the evaluation method for ecosystem service value based on per unit area. J. Nat. Resour. $30,1243-1254$.

Xie, G., Zhang, C., Zhen, L., Zhang, L., 2017. Dynamic changes in the value of China's ecosystem services. Ecosyst. Serv. 26, 146-154.

Yan, Y., Zhu, J.Y., Wu, G., Zhan, Y.J., 2017. Review and prospective applications of demand, supply, and consumption of ecosystem services. Acta Ecol. Sinica 37, 2489-2496.

Zhang, Y.G., Guan, W., Li, C.P., Dong, L.J., 2002. A study on the exploition and the sustainable utilization of marine resources in the Bohai Sea. J. Nat. Resour. 17, 768-775.

Zhang, Z.H., Lu, J.B., Ye, S.F., Zhu, M.Y., 2015a. Values of marine ecosystem services in Sanggou Bay. Chin. J. Appl. Ecol. 18, 2540-2547.

Zhang, H.L., Zhang, J.M., 2014. The main types of marine ecological disasters and their distribution status in the North China Sea. Acta Laser Biol. Sinica 23, 566-571.

Zhang, Y.S., Zhao, L., Liu, J.Y., Liu, Y.L., Li, C.S., 2015b. The impact of land cover change on ecosystem service values in urban agglomerations along the coast of the Bohai Rim, China. Sustainability 7, 10365-10387. 